\title{
La prestación por cese de actividad en las sociedades cooperativas de trabajo asociado
}

\author{
Francisco Javier Arrieta Idiakez \\ Profesor de Derecho del Trabajo \\ Universidad de Deusto
}

Recibido: 25.07.2012

Aceptado: 10.09.2012

Sumario: I. El encuadramiento de las sociedades cooperativas en el Sistema de Seguridad Social como requisito previo que condiciona la posibilidad de inclusión en el ámbito subjetivo de protección por cese de actividad de los trabajadores autónomos. II. Ámbito subjetivo de la protección por cese de actividad. III. Objeto de la acción protectora por cese de actividad. IV. Requisitos necesarios para el nacimiento del derecho a la protección por cese de actividad. V. Acción protectora. VI. Gestión de la contingencia por cese de actividad. VII. Dinámica de la protección por cese de actividad. VIII. Régimen de obligaciones, infracciones y sanciones.

Resumen: El presente trabajo tiene por objeto analizar las consecuencias de la regulación de la prestación por cese de actividad, como nueva situación protegida por el Sistema de Seguridad Social, en el ámbito de los trabajadores autónomos, en lo que respecta a los socios de trabajo de las Cooperativas de Trabajo Asociado. En concreto, la regulación de dicha situación se analiza desde las particularidades que caracterizan a tales socios.

Palabras clave: prestación por cese de actividad, cooperativas de trabajo asociado, trabajadores autónomos.

Abstract: This paper aims to examine the consequences of the provisions that regulate the Termination of an Activity for self-employed workers. In particular, the new protection afforded through the Social Security System to members of a Cooperative Society of Associated Labour, with the focus being on regulations that may affect its members.

Key words: employment benefits attributable to a termination of an activity, cooperative societies of associated labour, self-employed. 


\section{El encuadramiento de las sociedades cooperativas en el Sistema de Seguridad Social como requisito previo que condiciona la posibilidad de inclusión en el ámbito subjetivo de protección por cese de actividad de los trabajadores autónomos}

Las reglas generales a tener en cuenta para el correcto encuadramiento de las sociedades cooperativas en el Sistema de Seguridad Social se regulan expresamente en el Real Decreto 1/1994, de 20 de junio, por el que se aprueba el Texto Refundido de la Ley General de la Seguridad Social (TRLGSS) ${ }^{1}$.

De acuerdo con dichas reglas, deben distinguirse los distintos tipos de cooperativas, en razón de la actividad y las diversas relaciones que se puedan dar entre los socios, como persona física, y la sociedad cooperativa, como persona jurídica: socios trabajadores en las de trabajo asociado, socios de explotación comunitaria de la tierra y socios de trabajo en las demás².

Así, en primer lugar, el artículo 7 del TRLGSS se limita a señalar que los socios trabajadores de cooperativas de trabajo asociado se encuentran comprendidos en el Sistema de Seguridad Social.

En segundo lugar, la Disposición Adicional cuarta del TRLGSS, bajo la rúbrica «modalidades de integración de los socios trabajadores y de los socios de trabajo de las cooperativas» aporta algo más de claridad a la situación.

Respecto a los socios trabajadores de las Cooperativas de Trabajo Asociado, el TRLGSS viene a reproducir la clásica posibilidad de elección concedida a las sociedades cooperativas, según las cual éstas, en sus estatutos, podrán optar entre las modalidades siguientes ${ }^{3}$ :

a) Como asimilados a trabajadores por cuenta ajena. Dichas cooperativas quedarán integradas en el Régimen General o en alguno de los Regímenes Especiales de la Seguridad Social, según proceda, de acuerdo con su actividad.

b) Como trabajadores autónomos en el Régimen Especial correspondiente.

1 BOE de 29 de junio de 1994, núm. 154.

2 Al respecto, véase López GANDía, J. "Las prestaciones de desempleo en las empresas de economía social. Especial referencia al pago único». En AS, 2002, vol. V, p. 1074.

3 Igualmente, cfr. artículo 8 del Real Decreto 84/1996, de 26 de enero, por el que se aprueba el Reglamento General sobre inscripción de empresas y afiliación, altas, bajas y variaciones de datos de trabajadores en la Seguridad Social (BOE de 27 de febrero de 1996, núm. 50). 
En cambio, el TRLGSS considera a los socios trabajadores de las cooperativas de explotación comunitaria de la tierra, así como a los socios de trabajo del resto de las cooperativas, asimilados a trabajadores por cuenta ajena 4 .

Al fin y a la postre, esta disparidad de encuadramientos de las sociedades cooperativas en el Sistema de Seguridad Social no es baladí. Ello supone que tanto en el caso de que las cooperativas de Trabajo Asociado opten en sus estatutos por el encuadramiento de sus socios en el Sistema como asimilados a trabajadores por cuenta ajena, como en el caso del resto de cooperativas, que por imperativo legal deben encuadrar a sus socios en el Sistema como asimilados a trabajadores por cuenta ajena, se proteja la contingencia de desempleo en los términos establecidos por el Real Decreto 1043/1985, de 19 de junio, por el que se amplía la protección por desempleo a los socios trabajadores de Cooperativas de Trabajo Asociado ${ }^{5}$. En cambio, la opción de las Cooperativas de Trabajo Asociado por encuadrar a sus socios como trabajadores autónomos en el Régimen Especial correspondiente ha supuesto históricamente su desprotección frente a la contingencia de desempleo, dado que todos los trabajadores autónomos o por cuenta propia, cualesquiera que fueran los Regímenes en que hubieran quedado encuadrados, han permanecido excluidos de la protección de dicha contingencia ${ }^{6}$.

Con todo, la aprobación de la Ley 32/2010, de 5 de agosto, por la que se establece un sistema específico de protección por cese de actividad de los trabajadores autónomos ${ }^{7}$, supone poner fin a la des-

4 Cfr. apartado 2 de la Disposición Adicional 4 del TRLGSS. Ahora bien, debe tenerse en cuenta que las cooperativas que, al amparo de la Disposición Transitoria 7 de la Ley 3/1987, de 2 de abril, General de Cooperativas, optaron por mantener la asimilación de sus socios de trabajo a trabajadores autónomos, a efectos de Seguridad Social, conservarán el derecho de opción mencionado anteriormente. No obstante, si con posterioridad a la fecha de entrada en vigor del TRLGSS, la cooperativa modificara el régimen de encuadramiento de sus socios de trabajo, para su incorporación como trabajadores por cuenta ajena, en el régimen que corresponda, no podrá volver a ejercitar el derecho de opción.

${ }^{5}$ BOE de 2 de julio de 1985, núm. 157. Para un estudio detallado de la evolución histórica de la protección por desempleo en las sociedades cooperativas y el análisis de dicho Real Decreto, véase ARRIETA IDIAKEZ, F.J. «El desempleo en la sociedad cooperativa». En VV.AA. Derecho de Sociedades. Congreso UNIJES 2007. Tomo II (Llebaría SAMPer, S., dir.). Barcelona: Bosch, 2008, pp. 205-222.

6 SÁnCHEZ-Urán AZAÑA, Y. «El desempleo de los trabajadores autónomos. Un estudio de la Ley 32/2010, de 5 de agosto, por la que se establece un sistema específico de protección por cese de actividad de los trabajadores autónomos». Madrid: Civitas, 2010, p. 40 .

7 BOE de 6 de agosto de 2010, núm. 190. 
protección que sufrían en el Sistema público de Seguridad Social los trabajadores autónomos y, por ende, los socios trabajadores de las Cooperativas de Trabajo Asociado, cuando sus cooperativas optaban en los estatutos por encuadrarlos como trabajadores autónomos en el Régimen Especial correspondiente ${ }^{8}$.

No obstante, debe advertirse que la Ley 32/2010 no supone la extensión de la protección por desempleo a los trabajadores por cuenta propia o autónomos, sino que crea una nueva contingencia específica para los mismos: el cese de actividad ${ }^{\text {. }}$.

Por ello, a continuación se profundizará en la caracterización de la contingencia de cese de actividad, con el objetivo de analizar los requisitos que deben cumplir los socios trabajadores de Cooperativas de Trabajo Asociado para poder disfrutar de los beneficios derivados de su acción protectora.

\section{II. Ámbito subjetivo de la protección por cese de actividad}

En principio, la protección por cese de actividad alcanza a los trabajadores autónomos comprendidos en el Régimen Especial de los Tra-

8 En torno a la creación de la prestación por cese de actividad, pueden consultarse VALDÉS DAL-RE, F. «El sistema de protección por cese de actividad del trabajo autónomo: propuestas para una futura regulación». En RDS, 2009, núm. 45, pp. 25-46; JOVER RAMíREZ, C. "El informe sobre la protección por cese de actividad: promoción del trabajo autónomo, prestación y jubilación, gestión y régimen sancionador». En DL, 2009, núm. 87, pp. 109-136; PURCALLA Bonilla, M.A. «Trabajo autónomo y prestación por cese de actividad: la reforma anunciada sobre el "desempleo" de los trabajadores autónomos». En CEF: Revista de Trabajo y Seguridad Social, 2009, núm. 312, pp. 103-141; CAVAS MARTínez, F. "La protección por cese de actividad de los trabajadores autónomos». En $A S, 2010$, núm. 15, pp. 11-22.

9 Sin duda, con el objetivo de dejar claro que esta nueva contingencia se constituye de manera autónoma e independiente respecto a la contingencia de desempleo, el legislador se refiere en la denominación de la Ley 32/2010 a "un sistema específico de protección por cese de actividad». En ese sentido, como ha afirmado SÁnCHEZ-URÁn AZAÑA, «la expresión o término «sistema» parece querer referirse a la configuración legal coordinada, normativa y procedimental, de un sistema jurídico propio y al margen de la protección por desempleo, contingencia comprendida en la acción protectora del Sistema de Seguridad Social...». Pero como acertadamente critica la misma autora, «una cosa es que se pretenda idear una protección específica «por desempleo» para los trabajadores autónomos y otra que sea razonable utilizar expresiones innecesarias y no coincidentes con la realidad de la garantía institucional de un único Sistema de protección social pública de las necesidades sociales, es decir el Sistema de Seguridad Social» (SÁNCHEZ-URÁn AZAÑA, Y., ob. cit., p. 48). 
bajadores por Cuenta Propia o Autónomos ${ }^{10}$, entre los que se encuentran también los incluidos en el Sistema Especial de Trabajadores por Cuenta Propia Agrarios, y a los trabajadores por cuenta propia incluidos en el Régimen Especial de los Trabajadores del Mar ${ }^{11}$.

Por consiguiente, independientemente del Régimen Especial en el que, en su caso, las Cooperativas de Trabajo Asociado decidan encuadrar a sus socios como trabajadores autónomos - obviamente, en función de la actividad desarrollada-, los socios trabajadores serán sujetos potencialmente protegibles frente al cese de actividad; potencialmente, porque para que la protección llegue a materializarse los socios —al igual que cualquier otro trabajador autónomo- deberán cumplir una serie de condiciones (infra 4, 5, 6 y 7). Curiosamente, una de esas condiciones debe traerse a colación aquí, a saber, tener cubiertas las contingencias profesionales ${ }^{12}$, ya que si se tienen cubiertas tales

10 Debe tenerse en cuenta el Decreto 2530/1970, de 20 de agosto, por el que se regula el régimen especial de la Seguridad Social de los Trabajadores por Cuenta Propia o Autónomos (BOE de 15 de septiembre de 1970, núm. 221).

11 Cfr. artículo 2.1 de la Ley 32/2010.

En relación a los trabajadores autónomos incluidos en el Sistema Especial de Trabajadores por Cuenta Propia Agrarios debe estarse a lo regulado en la Ley 18/2007, de 4 de julio, por la que se procede a la integración de los trabajadores por cuenta propia del Régimen Especial Agrario de la Seguridad Social en el Régimen Especial de la Seguridad Social de los Trabajadores por Cuenta Propia o Autónomos (BOE de 5 de julio de 2007, núm. 160). En concreto, a efectos de que les sea de aplicación la protección por cese de actividad se estará a lo establecido en la Disposición Adicional quinta del Real Decreto 1541/2011, de 31 de octubre, por el que se desarrolla la Ley 32/2010, de 5 de agosto, por la que se establece un sistema específico de protección por cese de actividad de los trabajadores autónomos (BOE de 1 de noviembre de 2011, núm. 263), con la particularidad de que dicha protección solamente ha sido posible a partir del 1 de enero de 2012, pues el Real Decreto 1541/2011 entró en vigor para este colectivo en dicha fecha (Disposición Final tercera), y la regulación reglamentaria resultaba la condición sine qua non para la extensión de la protección por cese de actividad a los trabajadores autónomos incluidos en el Sistema Especial para trabajadores por cuenta propia agrarios (artículo 2.1 de la Ley 32/2010, en relación con Disposición Adicional octava de la misma norma).

Respecto a los trabajadores autónomos incluidos en el Régimen Especial del Mar debe estarse a lo regulado en los artículos 2.b) y 3 del Decreto 2864/1974, de 30 de agosto, por el que se aprueba el texto refundido de las Leyes 116/1969, de 30 de diciembre, y 24/1972, de 21 de junio, por el que se regula el Régimen Especial de la Seguridad Social de los Trabajadores del Mar (BOE de 10 de octubre de 1974, núm. 243), así como en los artículos 2.b), y 3 a 6 del Decreto 1867/1970, de 9 de julio, por el que se aprueba el Reglamento General de la Ley 116/1969, de 30 de diciembre, por la que se regula el Régimen Especial de la Seguridad Social de los Trabajadores del Mar (BOE de 11 de julio de 1970, núm. 165).

12 LASAOSA IRIGOYEN advierte que la exigencia de tener cubiertas las contingencias profesionales para poder beneficiarse de la prestación por cese de actividad «es más un 
contingencias (sobre el carácter obligatorio/voluntario de dicha cobertura infra 4), en principio, existirá, también, la obligación de cotizar por la contingencia de cese de actividad, para que, cuando llegado el momento, y cumpliéndose el resto de condiciones exigidas, el socio trabajador pueda beneficiarse de la acción protectora regulada respecto a esta última contingencia. Pero, aun así, la protección por cese de actividad no resultará obligatoria en el caso de socios de cooperativas comprendidas en el Régimen Especial de los Trabajadores por Cuenta Propia o Autónomos, siempre que estas cooperativas dispongan de un sistema intercooperativo de prestaciones sociales, complementario al Sistema público, que establezca un nivel de cobertura, en lo que respecta a las situaciones de cese de actividad, al menos, equivalente al regulado en la Ley 32/2010

\section{Objeto de la acción protectora por cese de actividad}

La acción protectora por cese de actividad tiene por objeto la situación de aquellos trabajadores autónomos que, pudiendo y queriendo ejercer una actividad económica o profesional a título lucrativo hayan cesado en dicha actividad, siempre y cuando cumplan los requisitos necesarios para el nacimiento del derecho a la prestación derivada de tal situación ${ }^{14}$ (infra 4).

Auque ya pueda intuirse de lo que se acaba de señalar, en el artículo 5.3.a) de la Ley 32/2010, se menciona expresamente el carácter involun-

requisito de acceso que un criterio de determinación del ámbito subjetivo». Es más yerra al señalar que «el legislador no ha incluido el requerimiento de tener cubiertas las contingencias profesionales en el artículo 4, rubricado «Requisitos para el nacimiento del derecho a la prestación», sino en el 2, "Ámbito subjetivo de protección»», pues como veremos, el primero de los requisitos exigidos por el artículo 4 de la Ley 32/2010 consiste en "estar afiliados y en situación de alta y cubiertas las contingencias profesionales en... [alguno de los Regímenes Especiales que integran a los trabajadores por cuenta propia o autónomos]». En cambio, sí resulta acertada su conclusión, cuando se refiere, en relación con el artículo 2 de la Ley 32/2010, a la voluntad del legislador de «resaltar especialmente la íntima conexión que se establece entre la cobertura de las contingencias profesionales y la prestación por cese de actividad» (LASAOSA IRIGOYEN, E. La prestación por cese de actividad para trabajadores autónomos. Cizur Menor: Aranzadi, 2011, pp. 43-44).

13 Cfr. artículo 2.3 de la Ley 32/2010. Además, téngase en cuenta que esta excepción a la obligación de proteger la contingencia de cese de actividad solamente podrá ejercitarse a partir del 1 de enero de 2013, en virtud de lo establecido en la Ley 27/2011, de 1 de agosto, sobre actualización, adecuación y modernización del Sistema de Seguridad Social (BOE de 2 de agosto de 2011, núm. 184).

14 Cfr. artículo 1.1 de la Ley 32/2010. 
tario que debe revestir el cese para ser merecedor de protección. Es más, también se exige al trabajador afectado por dicha situación una voluntad real de incorporarse al mercado de trabajo, como condición para poder seguir beneficiándose de la prestación económica concedida ${ }^{15}$.

Por lo demás, resulta evidente que la actividad cuyo cese constituye la contingencia protegida debe ser aquélla que, en su momento, fue determinante del encuadramiento en el Régimen Especial de los Trabajadores por Cuenta Propia o Autónomos o en el Régimen Especial de los Trabajadores del Mar ${ }^{16}$.

Ahora bien, debe tratarse de un cese total, es decir, se excluye el cese parcial o la reducción del tiempo de trabajo ${ }^{17}$. Pero, en íntima conexión con estas últimas ideas, debe matizarse que, de existir supuestos de pluriactividad, parece obvio que el cese no deberá producirse en aquellas actividades que nada tengan que ver con la que pretende causar la prestación por cese de actividad. Con otras palabras la incompatibilidad entre la prestación y el trabajo realizado actúa tras el reconocimiento de la prestación, en lo que respecta al disfrute de la misma. A ello nos referiremos posteriormente, con mayor detenimiento (infra 7).

Por último, el cese de actividad puede ser definitivo o temporal ${ }^{18}$.

\section{Requisitos necesarios para el nacimiento del derecho a la protección por cese de actividad}

El derecho a la protección por cese de actividad se reconoce a aquellos trabajadores autónomos en los que concurren los requisitos que se enumeran a continuación ${ }^{19}$.

a) A la fecha del cese de actividad deben estar afiliados, en situación de alta y cubiertas las contingencias profesionales y la de cese de

15 Cfr. artículo 4.1.c) de la Ley 32/2010.

16 Cfr. artículo 1.2 de la Ley 32/2010.

17 Ibidem.

18 Cfr. artículo 1.3 de la Ley 32/2010. Al respecto, vid. Cervilla Garzón, M.J. «El esperado informe sobre la prestación por cese de actividad: análisis del ámbito subjetivo, hecho causante, dinámica, cuantía y diseño financiero». En DL, 2009, núm. 87, p. 95.

19 Cfr. artículo 4 de la Ley 32/2010, en relación con el artículo 2 del Real Decreto 1541/2011. Igualmente, debe matizarse, conforme a lo establecido en la Disposición Adicional quinta del Real Decreto 1541/2011, que tales requisitos también resultan de aplicación a los trabajadores incluidos en el Sistema Especial para trabajadores por cuenta propia agrarios, aunque con las particularidades que se establecen en dicho precepto, en lo que respecta a la concreción de la situación legal de cese de actividad que los mismos deben acreditar. 
actividad en el Régimen Especial de los Trabajadores por Cuenta Propia o Autónomos o, en su caso, en el Régimen Especial de los Trabajadores del Mar, como trabajadores autónomos ${ }^{20}$.

b) Deben solicitar la baja en el Régimen Especial correspondiente a causa del cese de actividad.

c) Deben tener cubierto un período de cotización de 48 meses anteriores a la situación legal de cese de actividad, de los cuales, al menos, 12 deben ser continuados e inmediatamente anteriores a dicha situación de cese, sin perjuicio de considerar a tales efectos el mes en que se produzca la misma.

d) Encontrarse en situación legal de cese de actividad ${ }^{21}$. A tales efectos, es necesario concretar el significado de situación legal de cese

20 Conforme a la Disposición Transitoria única de la Ley 32/2010, se establece un plazo especial para optar a la cobertura de las contingencias profesionales por parte de aquellos trabajadores que en la fecha de entrada en vigor de la ley (6 de noviembre de 2010) figuren en alta en el Régimen Especial de los Trabajadores por Cuenta Propia o Autónomos y no tengan cubierta la protección por contingencias profesionales. En concreto, el plazo para optar por dicha cobertura es el de los 3 meses siguientes a la entrada en vigor de la ley (6 de febrero de 2011), con efectos desde el día primero del mes siguiente al de dicha opción. En verdad, la interpretación de este precepto no es fácil. Parece que se libera, a los autónomos afiliados con anterioridad a la entrada en vigor de la Ley 32/2010 al Régimen Especial de los Trabajadores Por Cuenta Propia o Autónomos, de la obligación de cotizar por la prestación por cese de actividad, pues como se ha visto anteriormente, el mero hecho de tener aseguradas/protegidas las contingencias profesionales conlleva la necesidad de asegurar/proteger también el cese de actividad; o si se prefiere, dicho en otros términos, la protección del cese de actividad conlleva la previa protección de las contingencias profesionales. Por otro lado, tampoco cabe olvidar que si bien los trabajadores autónomos ordinarios no están obligados a asegurar las contingencias profesionales, parece claro que tras la entrada en vigor de la Ley 32/2010, deberán hacerlo si desean proteger el cese de actividad. Cosa realmente improbable, por la sencilla razón de que quien no desea aspirar a una protección mínima parece difícil que quiera aspirar a más protección, lo que equivale a más cotizaciones/costes empresariales. Es más, existe el riesgo de que esta nueva medida actúe como un fenómeno de desincentivación a la hora de proteger las contingencias profesionales. Igualmente, debe recordarse que para los autónomos agrarios la cobertura de riesgos profesionales es obligatoria respecto a las contingencias de incapacidad permanente y muerte y supervivencia, sin perjuicio de proteger voluntariamente la totalidad de las contingencias derivadas de riesgos profesionales (artículo 47 bis. 5 del Real Decreto 84/1996, de 26 de enero); y que los trabajadores autónomos del Régimen Especial de los Trabajadores del Mar están obligados a concertar la cobertura de las contingencias profesionales bien con el Instituto Social de la Marina, bien con una Mutua (artículo 48.4 del Real Decreto 84/1996, de 26 de enero).

21 Al respecto resulta de máximo interés, pese a referirse al análisis de la situación legal de cese de actividad referida al común de los autónomos, obviando por tanto las particularidades existentes, entre otros, en el ámbito de los socios trabajadores de las Cooperativas de Trabajo Asociado, Viqueira Pérez, C. «La situación legal de cese de actividad. Análisis de las causas comunes». En RDS, 2011, núm. 55, pp. 85-108. 
de actividad, más si cabe teniendo en cuenta que en el supuesto de los socios de trabajo de las Cooperativas de Trabajo Asociado se regulan con carácter particular o especial las causas de tal situación, así como los medios para acreditarlas.

En concreto, se considerarán en situación legal de cese de actividad los socios trabajadores que se encuentren en alguno de los siguientes supuestos, aunque se trate de aspirantes a socios en período de prueba22:

a) Los que hubieren cesado, con carácter definitivo o temporal, en la prestación y, por tanto, en la actividad desarrollada en la cooperativa, perdiendo los derechos económicos derivados directamente de dicha prestación por alguna de las siguientes causas:

- Por expulsión improcedente de la cooperativa. Nótese que a diferencia de lo que ocurre con los despidos en las relaciones laborales, se sigue aquí el criterio establecido por el Real Decreto 1043/1985, de 19 de julio, por el que se amplia la protección por desempleo a los socios trabajadores de Cooperativas de Trabajo Asociado ${ }^{23}$. Ello supone que para que los socios trabajadores accedan, bien a la prestación de desempleo, cuando se encuentren afiliados en el Régimen General, bien a la prestación por cese de actividad, cuando se encuentren afiliados en el Régimen Especial de Trabajadores por Cuenta Propia o Autónomos o en el Régimen Especial de los Trabajadores del Mar, solamente se acepta la expulsión improcedente, cuando en las relaciones laborales el despido calificado como procedente también da lugar al desempleo ${ }^{24}$. E incluso llama la atención, más si cabe, que para que los trabajadores autónomos económicamente dependientes (TRADEs) puedan acceder a la prestación por cese de actividad se acepta como situación legal de cese de actividad «el incumplimiento contractual grave del cliente, debidamente acreditado» ${ }^{25}$. Parece que esta disparidad de regulaciones debería subsanarse en un sentido o en otro, y ello a pesar de que, como haya advertido la doctrina, la razón de ser de excluir respecto a los trabajadores autónomos ordina-

22 Cfr. Disposición Adicional sexta de la Ley 32/2010, en relación con el artículo 10.2 del Real Decreto 1541/2011.

23 Cfr. artículo 2.1.a).

24 Cfr. artículo 208.1.c) del TRLGSS.

25 Cfr. artículo 5.2.c) de la Ley 32/2010. 
rios la expulsión procedente o justificada, como situación legal de cese de actividad, radique en prevenir el fraude por connivencia entre los órganos gestores de la Cooperativa de Trabajo Asociado y el socio trabajador que quisiera abandonarla, ya que los mismos podrían acordar una expulsión procedente para que éste pudiera acogerse a la prestación por cese de actividad ${ }^{26}$.

- Por causas económicas, técnicas, organizativas, productivas o de fuerza mayor. De acuerdo con la Ley 27/1999, de 16 de julio, de Cooperativas ${ }^{27}$, debe recordarse que por tales causas cabe tanto la baja definitiva de los socios trabajadores afectados, como la suspensión temporal de las obligaciones y derechos de los mismos ${ }^{28}$. Igualmente, debe recordarse que, en el supuesto de cese total de la actividad de la cooperativa, si la misma cuenta con uno o más trabajadores por cuenta ajena, se requiere que previamente al cese de la actividad de los socios trabajadores se cumplan «las garantías y procedimientos regulados en la legislación laboral»29. A pesar de la ambigüedad de estos últimos criterios, parece que el legislador se refiere a las garantías que tienen que ver con el cese de la actividad, que para los trabajadores por cuenta ajena ha supuesto la finalización de sus contratos de trabajo $^{30}$. Por consiguiente, deberá estarse a las garantías que rigen para la extinción de los contratos de trabajo, a saber, las contempladas en los artículos 51, 52.c) y 53 del Real Decreto legislativo 1/1995, de 24 de marzo, por el que se aprueba el texto refundido de la Ley del Estatuto de los Trabajadores (TRLET) ${ }^{31}$, relativos a los despidos colectivos, por fuerza mayor y por causas objetivas. Por su parte, en el supuesto de concurso deberá estarse a los trámites previstos en el artículo 64 de la Ley 22/2003, de 9 de julio, Concursal ${ }^{32}$. Finalmente, en tales casos, se comunicará el cese total de la actividad de la cooperativa a la Tesorería General de la Seguridad Social o al Instituto Social de la Marina, dependiendo

26 LASAOSA IRIGOYEN, E., ob. cit., p. 81.

27 BOE de 17 de julio de 1999, núm. 170.

28 Cfr. artículos 85 y 84.3, respectivamente, de la Ley 27/1999.

29 Cfr. Disposición Adicional sexta, apartado quinto, de la Ley 32/2010.

30 En el mismo sentido LASAOSA IRIGOYEN, E., ob. cit., p. 99.

31 BOE de 29 de marzo de 1995, núm. 75.

32 BOE de 10 de julio de 2003, núm. 164. 
de los casos, así como las bajas en el correspondiente régimen de la Seguridad Social de los trabajadores a cargo de la cooperativa, en los términos de los artículos 18 y 29.1 del Reglamento General sobre inscripción de empresas y afiliación, altas, bajas y variaciones de datos de trabajadores en la Seguridad Social, aprobado por el Real Decreto 84/1986, de 26 de enero 33 (cfr. artículo 2.2 del Real Decreto 1541/2011).

- Por finalización del período al que se limitó el vínculo societario de duración determinada.

- Por causa de violencia de género, en las socias trabajadoras.

- Por pérdida de licencia administrativa de la cooperativa.

b) Los aspirantes a socios en período de prueba que hubieran cesado en la prestación de trabajo durante el mismo por decisión unilateral del Consejo Rector u órgano de administración correspondiente de la cooperativa.

Por su parte, tales causas deben acreditarse mediante los siguientes documentos 34 :

i) La expulsión improcedente de la cooperativa, mediante la notificación del acuerdo de expulsión por parte del Consejo Rector de la cooperativa u órgano de administración correspondiente, indicando su fecha de efectos, y en todo caso el acta de conciliación judicial o la resolución definitiva de la jurisdicción social o civil, dependiendo de si las cuestiones contenciosas sobre la expulsión del socio afectan a incumplimientos relativos a su prestación de trabajo o a sus obligaciones económicas ${ }^{35}$. En este sentido, debe subrayarse que es necesario que el socio trabajador presente demanda judicial y que se haya llegado a la fase de conciliación judicial o a la sentencia firme que resuelva el procedimiento, para que exista constancia de la improcedencia de la expulsión. Ello significa que en el ámbito de la prestación por cese de actividad, al igual que ocurre en el ámbito de la prestación por desempleo de los socios trabajadores afiliados al Régimen General, no se acepta la conciliación administrativa previa o extrajudicial como medio de acreditación de la situa-

33 BOE de 27 de febrero de 1996, núm. 50.

34 No debe olvidarse la posibilidad que brinda la Disposición adicional primera del Decreto 1541/2011 de que el solicitante de la protección por cese de actividad acompañe a su solicitud cualquier documento que estime oportuno para acreditar la concurrencia de la situación legal de cese de actividad ante el órgano gestor correspondiente.

35 Cfr. artículo 87 de la Ley 27/1999. 
ción legal de cese de actividad. Igualmente, resulta significativo que, en los casos de desempleo, para la acreditación de su situación basta con la notificación del acuerdo de expulsión por parte del Consejo Rector de la cooperativa, indicando su fecha de efectos ${ }^{36}$, mientras que en el caso del cese de actividad se requiere «en todo caso» el acta de conciliación judicial o la resolución definitiva de la jurisdicción competente que declare expresamente la improcedencia de la expulsión.

ii) Las causas económicas, técnicas, organizativas o productivas por parte de la sociedad cooperativa se acreditan mediante certificación literal del acuerdo de la Asamblea General o, en su caso, del Consejo Rector si así lo establecen los Estatutos por el que se designan los socios trabajadores concretos que deben causar baja en la cooperativa. Además, si el cese de actividad de los socios trabajadores comporta el cierre del establecimiento al público debe acreditarse tal extremo mediante alguno de los siguientes documentos:

- Documentación acreditativa del cese en el suministro y consumo de servicios inherentes al desarrollo de la actividad realizada en el establecimiento, tales como agua y electricidad.

- Documentación acreditativa de la extinción, cese o traspaso de las licencias, permisos o autorizaciones administrativas que fueran necesarios para el ejercicio de la actividad.

- Documentación acreditativa de la situación de baja como sujeto pasivo de las obligaciones fiscales devengadas como consecuencia del ejercicio de la actividad en el establecimiento.

- Documentación acreditativa del cese en la titularidad de la propiedad, alquiler, usufructo, traspaso o cualquier otro derecho que habilitara al ejercicio de la actividad en el establecimiento.

- En el caso de los trabajadores por cuenta propia del Régimen Especial del Mar titulares de embarcaciones debe procederse a depositar el Rol de la misma en la correspondiente Capitanía Marítima, lo que se acreditará con un certificado expedido a tal efecto.

Asimismo, junto a dicha certificación, deben presentarse los oportunos documentos de carácter contable, profesional, fiscal

36 Cfr. articulo 3.a) del Real Decreto 1043/1985. 
(v.gr. declaraciones del Impuesto sobre la Renta de las Personas Físicas y del Impuesto sobre el Valor Añadido, o certificado de la Agencia Estatal de la Administración Tributaria o autoridad competente de las comunidades autónomas, en el que se recojan los ingresos percibidos), administrativo o judicial, aportados por la sociedad cooperativa, en los que se hará constar la fecha de producción de los correspondientes motivos económicos, técnicos, productivos u organizativos.

iii) La fuerza mayor se acreditará mediante la declaración expedida por los órganos gestores correspondientes al lugar en que se ubique territorialmente el negocio, en la que deberá constar la fecha de la producción de la fuerza mayor, la documentación en la que se detalle, mediante los medios de prueba que se estimen necesarios, en qué consiste el suceso, su naturaleza imprevisible, o previsible pero inevitable, su relación con la imposibilidad de continuar con la actividad, indicando si la fuerza mayor es determinante del cese definitivo o temporal de la actividad y en este último caso, la duración del cese temporal aunque sea estimada, y cualesquiera otros aspectos que permitan al órgano gestor declarar tal circunstancia.

iv) La finalización del período al que se limitó el vínculo societario de duración determinada se acreditará mediante certificación del Consejo Rector u órgano de administración correspondiente de la baja en la cooperativa por dicha causa y su fecha de efectos.

v) El cese de actividad por causa de violencia de género en las socias trabajadoras se acreditará mediante la declaración escrita de la solicitante de haber cesado o interrumpido su prestación de trabajo en la sociedad cooperativa; dicha declaración se acompañará, además, de alguno de los siguientes documentos: auto de incoación de diligencias previas, auto acordando la adopción de medidas cautelares de protección a la víctima, auto acordando la prisión provisional del detenido, auto de apertura de Juicio oral, la orden de protección o informe o escrito de acusación del Ministerio Fiscal, o sentencia judicial condenatoria. Además, la declaración ha de contener la fecha a partir de la cual se ha producido el cese o la interrupción.

vi) El cese de actividad por extinción o revocación de licencia administrativa de la cooperativa se acreditará mediante la resolución de la extinción de las licencias, permisos o autorizaciones administrativas habilitantes para el ejercicio de la actividad, según la normativa vigente, en las que conste expresamente el mo- 
tivo de la extinción, y su fecha de efectos. Ahora bien, a tales efectos no se tienen en cuenta aquellas resoluciones en las que quede acreditado que la pérdida de la licencia venga motivada por incumplimientos contractuales o por la comisión de infracciones, faltas administrativas o delitos imputables al autónomo solicitante, u otros incumplimientos imputables al trabajador autónomo tendentes a la pérdida voluntaria de su licencia.

vii) El cese de actividad del aspirante a socio durante el período de prueba se acreditará mediante comunicación de no admisión por parte del Consejo Rector de la cooperativa u órgano de administración correspondiente.

Para finalizar con los aspectos sobre la situación legal de cese de actividad conviene traer a colación una medida antifraude que se regula para los casos de las bajas de los socios trabajadores ${ }^{37}$. Así, de acuerdo con dicha medida, no se consideran en situación legal de cese de actividad los socios trabajadores que, tras cesar definitivamente en la prestación de trabajo, y, por tanto, en la actividad desarrollada en la cooperativa, y haber percibido la prestación por cese de actividad, vuelven a ingresar en la misma sociedad cooperativa en un plazo de un año, a contar desde el momento en que se extinguió la prestación. En consecuencia, si el socio trabajador reingresase en la misma sociedad cooperativa en el plazo señalado, debería reintegrar la prestación percibida.

e) Acreditar activa disponibilidad para la reincorporación al mercado de trabajo, a través de las actividades formativas, de orientación profesional y de promoción de la actividad emprendedora a las que pueda convocarle el Servicio Público de Empleo correspondiente, o, en su caso, el Instituto Social de la Marina, para los trabajadores autónomos afiliados al Régimen Especial de los Trabajadores del Mar, mediante la suscripción del compromiso de actividad al que se refiere el artículo 231 del TRLGSS.

Como recuerda el legislador, con el fin de matizar el alcance de dicho compromiso de actividad, en el ámbito que nos atañe, el mismo debe suscribirse únicamente a fin de realizar las actividades formativas, de orientación profesional y de promoción de la actividad emprendedora mencionadas, y del cumplimiento de las obligaciones específicas establecidas en el artículo 17.1, apartados, g) y h), de la Ley 32/2010, de 5 de agosto, a saber ${ }^{38}$ :

37 Cfr. Disposición Adicional sexta de la Ley 32/2010.

38 Como acertadamente ha resaltado LASAOSA IRIGOYEN, nótese que en comparación con la exigencias establecidas por el artículo 231 del TRLGSS, respecto a la contingen- 
a) Comparecer a requerimiento del órgano gestor (infra 6) y estar a disposición del Servicio Público de Empleo de la correspondiente comunidad autónoma, o del Instituto Social de la Marina, a fin de realizar las actividades formativas, de orientación profesional y de promoción de la actividad emprendedora a las que se les convoque.

b) Participar en acciones específicas de motivación, información, orientación, formación, reconversión o inserción profesional para incrementar su ocupabilidad, que se determinen por el órgano gestor, por el Servicio Público de Empleo de la correspondiente Comunidad Autónoma, o por el Instituto Social de la Marina, en su caso.

f) No haber cumplido la edad ordinaria para causar derecho a la pensión contributiva de jubilación, salvo que el trabajador autónomo no tuviera acreditado el período de cotización requerido para ello.

A los efectos de acreditación de este requisito, para los trabajadores por cuenta propia del Régimen Especial del Mar, se considerará como edad ordinaria la inferior a la establecida por la ley que corresponda, por aplicación de los coeficientes reductores, de conformidad

cia de desempleo para con los trabajadores por cuenta ajena, la Ley 32/2010 y el Real Decreto 1541/2011, reguladoras de la prestación por cese de actividad, en primer lugar, no exigen a los trabajadores autónomos la obligación de «buscar activamente empleo», sino que se conforman con que el trabajador autónomo que pretende beneficiarse de la prestación por cese de actividad acredite «activa disponibilidad para la reincorporación al mercado de trabajo». En segundo lugar, tampoco imponen el deber de aceptar una colocación adecuada, como objeto del compromiso de actividad a suscribir por el trabajador autónomo. En suma, la referencia a la «activa disponibilidad para la reincorporación al mercado de trabajo» se limita a realizar las «actividades formativas, de orientación profesional y de promoción de la actividad emprendedora», sin que en ningún momento se pretenda obligar a los trabajadores autónomos a aceptar "ofertas de empleo adecuadas», y mucho menos de trabajo por cuenta ajena, a pesar de que así se estableciera en la primera redacción de la Ley 32/2010 (cfr. Disposición Final segunda), al modificar el artículo 25.4 del Real Decreto Legislativo 5/2000, de 4 de agosto, por el que se aprueba el texto refundido de la Ley de Infracciones y Sanciones en el Orden Social (BOE de 8 de agosto de 2000, núm. 189), con el fin de tipificar como infracción el rechazo de ofertas de empleo adecuadas también para los trabajadores autónomos solicitantes o beneficiarios de la prestación por cese de actividad. Como es sabido, esta modificación fue neutralizada antes de que entrase en vigor la Ley 32/2010, y concretamente durante la vacatio legis de la misma, a través del artículo 18. Nueve, de la Ley 35/2010, de 17 de septiembre, de Medidas Urgentes para la Reforma del Mercado de Trabajo (BOE de 18 de septiembre de 2010, núm. 227), al limitar la infracción por rechazar una oferta de empleo adecuada a los solicitantes o beneficiarios de prestaciones por desempleo de nivel contributivo o asistencial (vid. LASAOSA IRIGOYEN, E., ob. cit., pp. 91-97). 
con lo establecido en el artículo 1 del Real Decreto 1311/2007, de 5 de octubre, por el que se establecen nuevos criterios para determinar la pensión de jubilación del Régimen Especial de la Seguridad Social de los Trabajadores del Mar39, y en el Real Decreto 1851/2009, de 4 de diciembre, por el que se desarrolla el artículo 161 bis del TRLGS en cuanto a la anticipación de la jubilación de los trabajadores con discapacidad en grado igual o superior al $45 \% 40$.

g) Hallarse al corriente en el pago de las cuotas al correspondiente Régimen Especial de la Seguridad Social en la fecha del cese de actividad.

Pero, en el supuesto de que el trabajador autónomo no se hallara al corriente en el pago de las cuotas, debe aplicarse el artículo 28 del Decreto 2530/1970, de 20 de agosto, por el que se regula el Régimen Especial de la Seguridad Social de los Trabajadores por Cuenta Propia o Autónomos. Así, conforme a dicho precepto, si cubierto el período mínimo de cotización preciso para tener derecho a la prestación por cese de actividad, se solicitara ésta y la persona incluida en el campo de aplicación del Régimen Especial de Trabajadores por Cuenta Propia o Autónomos o del Régimen Especial de los Trabajadores del Mar no estuviera al corriente en el pago de las restantes cuotas exigibles en la fecha en que se entienda causada la prestación, la entidad gestora correspondiente (infra 6) invitará al interesado para que en el plazo improrrogable de 30 días naturales a partir de la invitación ingrese las cuotas debidas.

En ese sentido, si el interesado, atendiendo la invitación, ingresase las cuotas adeudadas dentro del plazo señalado anteriormente, se le considerará al corriente en las mismas a efectos de la prestación solicitada. Si el ingreso se realizase fuera de dicho plazo, deben tenerse en cuenta las siguientes dos reglas:

1. Como norma general, se concederá la prestación con efectos a partir del día primero del mes siguiente a aquel en que tuvo lugar el ingreso de las cuotas adeudadas.

2. Dado que cabe también el pago único de la prestación por cese de actividad (infra 5), en dicho caso se concederá la prestación menos un $20 \%$.

Por último, para justificar el ingreso de las cuotas dentro del plazo señalado, el trabajador autónomo presentará ante el órgano gestor un

39 BOE de 24 de octubre de 2007, núm. 255.

40 BOE de 22 de diciembre de 2009, núm. 307. 
certificado de la Tesorería General de la Seguridad Social de estar al corriente en el pago de sus cuotas.

\section{Acción protectora}

La acción protectora frente al cese de actividad se concreta en una prestación económica y en el abono de la cotización de Seguridad Social durante la percepción de la prestación por cese de actividad:

a) En lo que se refiere a la prestación económica41, la Base Reguladora será el promedio de las bases por las que hubiera cotizado durante los 12 meses continuados e inmediatamente anteriores a la situación legal de cese, computando a tal efecto el mes completo en el que se produzca esa situación. Al respecto, debe tenerse en cuenta que la Base de Cotización por cese de actividad se corresponderá con la Base de Cotización del Régimen Especial de los Trabajadores por Cuenta Propia o Autónomos que hubiere elegido, como propia, el trabajador autónomo con arreglo a lo establecido en las normas de aplicación, o bien la que le corresponda como trabajador por cuenta propia en el Régimen Especial de los Trabajadores del Mar. El tipo de cotización correspondiente a la protección por cese de actividad será del 2,2 por ciento $^{42}$. No obstante, debe matizarse que los trabajadores autónomos acogidos al sistema de protección por cese en la actividad tendrán una reducción de 0,5 puntos porcentuales en la cotización por la cobertura de incapacidad temporal, derivada de contingencias comunes ${ }^{43}$.

Por su parte, la cuantía de la prestación, durante todo su período de disfrute, se determinará aplicando a la Base Reguladora el 70\%.

Ahora bien, aun calculada la prestación conforme a tales criterios, la cuantía resultante de tales operaciones debe entrar dentro de las siguientes cuantías, que constituyen los topes máximos y mínimos de la prestación ${ }^{44}$ :

41 Cfr. artículo 9 de la Ley 32/2010, en relación con el artículo 13 del Real Decreto $1541 / 2011$.

42 Cfr. artículo 14, apartados 2 y 3 de la Ley 32/2010.

43 Cfr. Disposición Adicional segunda de la Ley 32/2010.

44 A los efectos de calcular las cuantías máxima y mínima, se entenderá que se tienen hijos a cargo, cuando éstos sean menores de 26 años, o mayores con una discapacidad en grado igual o superior al 33\%, carezcan de rentas de cualquier naturaleza iguales o superiores al SMI excluida la parte proporcional de las pagas extraordinarias, y convivan con el beneficiario.

Asimismo, a los mismos efectos, se tendrá en cuenta el IPREM mensual, incrementado en una sexta parte, vigente en el momento del nacimiento del derecho. 
a) La cuantía máxima de la prestación por cese de actividad será el $175 \%$ del IPREM, salvo cuando el trabajador autónomo tenga uno o más hijos a su cargo; en tal caso, la cuantía será, respectivamente, del $200 \%$ o del $225 \%$ de dicho indicador.

b) La cuantía mínima de la prestación por cese de actividad será del $107 \%$ o del $80 \%$ del IPREM, según el trabajador autónomo tenga hijos a su cargo, o no.

Precisamente, para fijar la cuantía máxima o mínima de la prestación se deben tener en cuenta las siguientes reglas:

1. La carencia de rentas de los hijos a cargo se presumirá en el caso de que éstos no realicen trabajos por cuenta propia o ajena o bien realizándolos no obtengan por ellos retribuciones iguales o superiores al SMI excluida la parte proporcional de las pagas extraordinarias.

2. No será necesaria la convivencia cuando el trabajador declare que tiene obligación de alimentos en virtud de convenio especial o resolución judicial, o que sostiene económicamente al hijo.

3. La cuantía máxima o mínima de la prestación por cese de actividad reconocida, se modificará por la variación en el número de hijos a cargo durante la percepción de la prestación.

4. A aquellos colectivos que conforme a las disposiciones que desarrollan las normas de cotización a la Seguridad Social hayan elegido una base mínima de cotización inferior a la base mínima ordinaria de cotización para los trabajadores por cuenta propia o autónomos, no les resultará de aplicación la cuantía mínima de la prestación por cese de actividad mencionada anteriormente.

Para finalizar con la prestación económica, hay que tener en cuenta que cabe la posibilidad de pago único de la prestación, conforme a las siguientes reglas 45 :

i) Quienes sean titulares del derecho a la prestación por cese de actividad, y tengan pendiente de recibir un período de, al menos, 6 meses, podrán percibir de una sola vez, el valor actual

45 Cfr. Disposición Adicional decimocuarta de la Ley 32/2010, en relación con la Disposición Adicional cuarta del Real Decreto 1541/2011. 
del importe de la prestación, cuando acrediten ante el órgano gestor que van a realizar una actividad profesional como trabajadores autónomos o socios trabajadores de una Cooperativa de Trabajo Asociado o sociedad que tenga el carácter de laboral.

ii) El beneficiario que desee percibir su prestación de una sola vez podrá solicitarlo al órgano gestor, acompañando a la solicitud memoria explicativa sobre el proyecto de inversión a realizar y actividad a desarrollar, así como cuanta documentación acredite la viabilidad del proyecto.

iii) En el caso de personas que deseen incorporarse como socios a Cooperativas de Trabajo Asociado o sociedades laborales deberán acompañar certificación de haber solicitado su ingreso en las mismas y condiciones en que éste se producirá. Si se trata de cooperativas o sociedades laborales de nueva creación deberán acompañar, además, el proyecto de estatutos de la sociedad. En estos casos el abono de la prestación en su modalidad de pago único estará condicionado a la presentación del acuerdo de admisión como socio o a la efectiva inscripción de la sociedad en el correspondiente registro.

iv) El órgano gestor, teniendo en cuenta la viabilidad del proyecto a realizar, reconocerá el derecho en el plazo de 30 días contados desde la solicitud del pago único. Contra la decisión del órgano gestor cabrá recurso en la jurisdicción social. La solicitud del abono de la prestación por cese de actividad, en todo caso deberá ser de fecha anterior a la fecha de incorporación a la cooperativa o sociedad laboral, o a la de constitución de la cooperativa o sociedad laboral, o a la de inicio de la actividad como trabajador autónomo, considerando que tal inicio coincide con la fecha que como tal figura en la solicitud de alta del trabajador en la Seguridad Social.

v) Una vez percibida la prestación por su valor actual el beneficiario deberá iniciar, en el plazo máximo de un mes, la actividad para cuya realización se le hubiera concedido y darse de alta en el correspondiente régimen de la Seguridad Social, o acreditar, en su caso, que está en fase de iniciación.

vi) El abono de la prestación se realizará de una sola vez por el importe que corresponda a las aportaciones al capital, incluyendo la cuota de ingreso, en el caso de las cooperativas, o al de la adquisición de acciones o participaciones del capital social en una sociedad laboral en lo necesario para acceder a la condición de socio trabajador, o a la inversión necesaria para desarro- 
Ilar la actividad en el caso de trabajadores autónomos, incluidas las cargas tributarias para el inicio de la actividad. Se abonará como pago único la cuantía de la prestación, calculada en días completos, de la que deducirá el importe relativo al interés legal del dinero.

vii) El órgano gestor, a solicitud de los beneficiarios de esta medida, podrá destinar todo o parte del pago único de la prestación por cese de actividad a cubrir los costes de cotización a la Seguridad Social. En tal caso, habrá que atenerse a las siguientes reglas:

- Si no se obtiene la prestación por su importe total, el importe restante se podrá obtener conforme a lo establecido en la regla 2 siguiente. Asimismo, el beneficiario de la prestación podrá optar por obtener toda la prestación pendiente por percibir conforme a lo establecido en la regla 2 siguiente.

- El órgano gestor podrá abonar mensualmente el importe de la prestación por cese de actividad para subvencionar la cotización del trabajador a la Seguridad Social, y en este supuesto:

a) La cuantía de la subvención, calculada en días completos de prestación, será fija y corresponderá al importe de la aportación íntegra del trabajador a la Seguridad Social en el momento del inicio de la actividad sin considerar futuras modificaciones.

b) El abono se realizará mensualmente por la entidad u organismo gestor al trabajador, previa comprobación de que se mantiene en alta en la Seguridad Social en el mes correspondiente.

c) La percepción de la prestación en un pago único será compatible con otras ayudas que para la promoción del trabajo autónomo o la constitución o integración en cooperativas o sociedades laborales pudieran obtenerse.

d) La no afectación de la cantidad percibida a la realización de la actividad para la que se haya concedido será considerada pago indebido a los efectos de reintegrar las prestaciones percibidas. A estos efectos, se entenderá, salvo prueba en contrario, que no ha existido afectación cuando el trabajador, en el plazo de un mes, no haya acreditado haber iniciado, desde que hubiera percibido 
la prestación, la actividad para cuya realización se le hubiere concedido dicha prestación, y haberse dado de alta en el correspondiente régimen de la Seguridad Social.

b) Respecto al abono de la cotización de Seguridad Social durante la percepción de la prestación por cese de actividad, debe matizarse que la misma se refiere a la cotización por contingencias comunes, entre las que se incluye expresamente la incapacidad temporal, con la finalidad de eludir cualquier tipo de duda ${ }^{46}$.

Como no podía ser de otra manera, el abono de la cotización se efectuará por los mismos períodos en los que se perciba la prestación económica por cese de actividad.

Y, como particularidad, la Base de Cotización durante la percepción de las prestaciones por cese de actividad corresponde a la Base Reguladora de la prestación por cese de actividad, calculada en los términos antes mencionados, sin que, en ningún caso, la Base de Cotización pueda ser inferior al importe de la base mínima o base única de cotización vigente en el correspondiente régimen y de acuerdo con las circunstancias específicas concurrentes en el beneficiario. Ahora bien, aquellos colectivos que, durante la actividad, hayan cotizado por una base reducida, cotizarán por una Base de Cotización reducida, también durante la percepción de la prestación por cese de actividad.

Finalmente, cuando la violencia de género sea determinante del cese temporal o definitivo de la actividad de la trabajadora autónoma, y la duración de la protección por cese de actividad sea superior a 6 meses, la entidad u órgano gestor iniciarán la cotización a la Seguridad Social a partir del séptimo mes, sin perjuicio de que los 6 primeros serán considerados como de cotización efectiva a efectos de las prestaciones de Seguridad Social, según dispone el artículo 21.5 de la Ley Orgánica 1/2004, de 28 de diciembre, de Medidas de Protección Integral contra la Violencia de Género. ${ }^{47}$

46 Recuérdese que a partir del 1 de enero de 2008 [Disposición Adicional tercera de la Ley 20/2007, de 11 de julio (BOE de 12 de julio de 2007, núm. 166), en relación con el artículo 47.2 del Real Decreto 84/1996, de 26 de enero] existe la obligación de asegurar la incapacidad temporal derivada de riesgos comunes. Aunque debe matizarse que para los autónomos agrarios (ahora encuadrados en el Sistema Especial para trabajadores por cuenta propia agrarios establecido dentro del Régimen Especial de los Trabajadores por Cuenta Propia o Autónomos) la cobertura por incapacidad temporal es voluntaria. Por su parte, los autónomos del mar (afiliados al Régimen Especial de Trabajadores del Mar) están obligados a asegurar la incapacidad temporal derivada de riesgos comunes.

47 BOE de 29 de diciembre de 2004, núm. 313. 


\section{Gestión de la contingencia por cese de actividad}

La gestión de la prestación económica por cese de actividad de los trabajadores autónomos corresponde, como norma general, a las Mutuas de Accidentes de Trabajo y Enfermedades Profesionales ${ }^{48}$. Ahora bien, en el supuesto de trabajadores autónomos que tengan cubierta la protección dispensada a las contingencias derivadas de accidentes de trabajo y enfermedades profesionales con una entidad gestora de la Seguridad Social, la gestión de esta prestación corresponderá49: en el ámbito del Régimen Especial de la Seguridad Social de los Trabajadores del Mar, al Instituto Social de la Marina, y en el ámbito del Régimen Especial de los Trabajadores por Cuenta Propia o Autónomos, al Servicio Público de Empleo Estatal ${ }^{50}$.

Por lo demás, conviene recordar que los socios trabajadores que se encuentren en situación legal de cese de actividad deben solicitar el reconocimiento del derecho a las prestaciones a tales órganos gestores hasta el último día del mes siguiente a la declaración de la situación legal del cese de actividad ${ }^{51}$. Y en caso de presentar la solicitud fuera del indicado plazo, siempre que el trabajador autónomo cumpla con el resto de requisitos legalmente previstos, se descontarán del período de percepción los días que medien entre la fecha en que debería haber presentado la solicitud y la fecha en que la presentó.

En cambio, las medidas de formación, orientación profesional y promoción de la actividad emprendedora de los trabajadores autónomos beneficiarios de la protección por cese de actividad deben gestionarse por el Servicio Público de Empleo correspondiente o, en su caso, por el Instituto Social de la Marina52.

48 Cfr. artículo 16.1 de la Ley 32/2010.

49 Conviene aclarar que esta situación existe residualmente como resultado de la evolución legislativa, en concreto de la que ha experimentado el artículo 47 del Real Decreto 84/1996, de 26 de enero. En efecto, en una redacción anterior a la dada por el Real Decreto 1273/2003, de 10 de octubre (BOE de 22 de octubre de 2003, núm. 253), el mencionado precepto permitía al trabajador autónomo asignar la cobertura de la incapacidad temporal bien a la entidad gestora correspondiente (Instituto Nacional de Seguridad Social o Instituto Social de la Marina) o bien a una Mutua. Y, en virtud del Real Decreto 1273/2003, de 10 de octubre, se pasó a permitir la cobertura de las contingencias profesionales por las mismas entidades que gestionaban la incapacidad temporal. En suma, el citado artículo 47 permitió durante un tiempo que los trabajadores autónomos encomendasen la gestión de sus contingencias profesionales al INSS o al ISM, razón por la que en la actualidad aún quedan afiliados en esa situación.

50 Cfr. Disposición Adicional cuarta de la Ley 32/2010.

51 Cfr. Disposición Adicional sexta, apartado 4, de la Ley 32/2010.

52 Cfr. artículo 14.4 de la Ley 32/2010. 


\section{Dinámica de la protección por cese de actividad}

La dinámica de la protección del cese de actividad se refiere al nacimiento, duración, suspensión, extinción y compatibilidad/incompatibilidad del derecho a la prestación por cese de actividad.

a) Nacimiento ${ }^{53}$ : el reconocimiento a la protección del cese de actividad conlleva el derecho a la prestación económica correspondiente a partir del primer día del segundo mes siguiente al hecho causante (fecha de efectos de la prestación). Por su parte, el derecho a que el órgano gestor competente abone la cuota de Seguridad Social por contingencias comunes nace a partir del primer día del mes siguiente al hecho causante, siempre que la solicitud de la prestación por cese de actividad se hubiera cursado dentro del plazo establecido ${ }^{54}$, pues, de lo contrario, el órgano gestor, se hará cargo a partir del mes siguiente al de la solicitud.

b) Duración ${ }^{55}$ : la duración de la prestación por cese de actividad estará en función de los períodos de cotización efectuados dentro de los 48 meses anteriores a la situación legal de cese de actividad de los que, al menos, 12 deberán ser continuados e inmediatamente anteriores a dicha situación de cese con arreglo a la siguiente escala56:

53 Cfr. artículo 7 de la Ley 32/2010, en relación con el artículo 11 del Real Decreto $1541 / 2011$.

54 Dicho plazo se extiende hasta el último día del mes siguiente al que se produjo el cese de actividad. No obstante, en las situaciones legales de cese de actividad causadas por motivos económicos, técnicos, productivos u organizativos, de fuerza mayor, así como por violencia de género, el plazo comenzará a computar a partir de la fecha que se hubiera hecho constar en los correspondientes documentos que acrediten la concurrencia de tales situaciones.

55 Cfr. artículo 8 de la Ley 32/2010, en relación con el artículo 12 del Real Decreto 1541/2011.

56 A los efectos de determinar el período de cotización exacto:

a) Se tendrán en cuenta exclusivamente las cotizaciones por cese de actividad efectuadas al Régimen Especial correspondiente;

b) se tendrán en cuenta las cotizaciones por cese de actividad que no hubieran sido computadas para el reconocimiento de un derecho anterior de la misma naturaleza;

(c) los meses cotizados se computarán como meses completos;

(d) las cotizaciones que generaron la última prestación por cese de actividad no podrán computarse para el reconocimiento de un derecho posterior. 


\begin{tabular}{lc}
\hline $\begin{array}{c}\text { Período de cotización } \\
\text { por meses }\end{array}$ & $\begin{array}{c}\text { Duración de la protección } \\
\text { por meses }\end{array}$ \\
\hline De 12 a 17 & 2 \\
De 18 a 23 & 3 \\
De 24 a 29 & 4 \\
De 30 a 35 & 5 \\
De 36 a 42 & 6 \\
De 43 a 47 & 8 \\
De 48 en adelante & 12 \\
\hline
\end{tabular}

No obstante, debe tenerse en cuenta que, en los casos de trabajadores autónomos entre 60 años (incluidos los trabajadores autónomos que tengan 60 años cumplidos en el momento de producirse el hecho causante del cese de actividad) y la edad en que se pueda causar derecho a la pensión de jubilación, se incrementará la duración de la prestación, conforme a la siguiente escala:

\begin{tabular}{lc}
\hline $\begin{array}{c}\text { Período de cotización } \\
\text { por meses }\end{array}$ & $\begin{array}{c}\text { Duración de la protección } \\
\text { por meses }\end{array}$ \\
\hline De 12 a 17 & 2 \\
De 18 a 23 & 4 \\
De 24 a 29 & 6 \\
De 30 a 35 & 8 \\
De 36 a 42 & 10 \\
De 43 en adelante & 12 \\
\hline
\end{tabular}

Además, el trabajador autónomo al que se le hubiera reconocido el derecho a la protección económica por cese de actividad podrá volver a solicitar un nuevo reconocimiento, siempre que concurran los requisitos legales y hubieren transcurrido 18 meses desde el reconocimiento del último derecho a la prestación.

Como normas complementarias a las anteriores, y aclarativas de las mismas deben citarse las siguientes:
a) La duración reconocida no se ampliará por el hecho de que el trabajador cumpla 60 años durante la percepción de la presta- ción.
b) En ningún caso se podrá aplicar el cómputo recíproco de cotiza- ciones por cese de actividad y de cotizaciones por desempleo.
c) La duración de la protección se reconocerá en meses y se con- sumirá por meses, salvo cuando concurran situaciones de des- 
cuento, reducción o reanudación de la prestación en las que el consumo de la duración de la prestación, y la cotización a la Seguridad Social, se podrá efectuar por días, considerando a esos efectos que cada mes está integrado por 30 días. No obstante, si la reanudación se produce por el cese de actividad en el trabajo autónomo el consumo de la duración y la cotización a la Seguridad Social se efectuará por meses.

d) No se podrá aplicar el cómputo reciproco de cotizaciones por cese de actividad entre el Régimen Especial de Trabajadores Autónomos y el Régimen Especial de Trabajadores del Mar.

c) Suspensión $n^{57}$ : el derecho a la protección por cese de actividad se suspenderá por el órgano gestor en los siguientes supuestos:

1. Durante el período que corresponda por imposición de sanción por infracción leve o grave, en los términos establecidos en el Real Decreto Legislativo 5/2000, de 4 de agosto, por el que se aprueba el Texto Refundido de la Ley sobre infracciones y sanciones en el orden social.

2. Durante el cumplimiento de condena que implique privación de libertad.

3. Durante el período de realización de un trabajo por cuenta propia o por cuenta ajena por tiempo inferior a 12 meses.

Tratándose de una suspensión, cabe la posibilidad de reanudar el percibo de la prestación, en los términos fijados en el artículo 10.3 de la Ley 32/2010, en relación con el artículo 15, apartados 2.5, del Real Decreto 1541/2011.

d) Extinción ${ }^{58}$ : el derecho a la protección por cese de actividad se extinguirá en los siguientes casos:

i) Por agotamiento del plazo de duración de la prestación.

ii) Por imposición de las sanciones en los términos establecidos en la Ley sobre infracciones y sanciones en el orden social.

iii) Por realización de un trabajo por cuenta ajena o propia durante un tiempo igual o superior a 12 meses, en este último

57 Cfr. artículo 10 de la Ley 32/2010, en relación con el artículo 15 del Real Decreto $1541 / 2011$.

58 Cfr. artículo 11 de la Ley 32/2010. 
caso siempre que genere derecho a la protección por cese de actividad como trabajador autónomo ${ }^{59}$.

iv) Por cumplimiento de la edad de jubilación ordinaria o, en el caso de los trabajadores por cuenta propia encuadrados en el Régimen Especial de los Trabajadores del Mar, edad de jubilación teórica, salvo cuando no se reúnan los requisitos para acceder a la pensión de jubilación contributiva. En este supuesto la prestación por cese de actividad se extinguirá cuando el trabajador autónomo cumpla con el resto de requisitos para acceder a dicha pensión o bien se agote el plazo de duración de la protección.

v) Por reconocimiento de pensión de jubilación o de incapacidad permanente, salvo que, en este último caso, se trate de una pensión de incapacidad permanente que sea compatible con el trabajo que dio lugar a la prestación por cese de actividad.

vi) Por traslado de residencia al extranjero, salvo en los casos que reglamentariamente se determinen.

vii) Por renuncia voluntaria al derecho.

viii) Por fallecimiento del trabajador autónomo.

e) Compatibilidad/incompatibilidad del derecho a la prestación por cese de actividad ${ }^{60}$ : comenzando por las incompatibilidades, y en sintonía con lo indicado al referirnos a las causas de extinción de la prestación por cese de actividad, en primer lugar, debe señalarse que el percibo de la misma resulta incompatible, como norma general, con el trabajo por cuenta propia, aunque su realización no implique la inclusión obligatoria en el Régimen Especial de los Trabajadores por Cuenta Propia o Autónomos o en el Régimen Especial de los Trabajadores del Mar, así como con el trabajo por cuenta ajena. En segundo lugar, será incompatible con la obtención de pensiones o prestaciones de carácter económico del Sistema de la Seguridad Social, salvo que éstas hubieran sido compatibles con el trabajo que dio lugar a la prestación por cese de actividad, así como con las medidas de fomento del cese de actividad reguladas por normativa sectorial para diferentes colectivos, o las

59 En este caso, el trabajador autónomo podrá optar, en el caso de que se le reconozca una nueva prestación, entre reabrir el derecho inicial por el período que le restaba y las bases y tipos que le correspondían, o percibir la prestación generada por las nuevas cotizaciones efectuadas. Cuando el trabajador autónomo opte por la prestación anterior, las cotizaciones que generaron aquella prestación por la que no hubiera optado no podrán computarse para el reconocimiento de un derecho posterior.

60 Cfr. artículos 12 y 13 de la Ley 32/2011, en relación con el artículo 17 de la Ley $1541 / 2011$. 
que pudieran regularse en el futuro con carácter estatal. Y, por lo que se refiere a los trabajadores por cuenta propia incluidos en el Régimen Especial de los Trabajadores del Mar, la prestación por cese de actividad será incompatible con la percepción de las ayudas por paralización de la flota.

El régimen de compatibilidades con el percibo de las prestaciones por otras contingencias se ciñe, básicamente, a las contingencias de incapacidad temporal y de maternidad y paternidad.

Así, en relación con la contingencia de incapacidad temporal deben considerarse las siguientes reglas:

a) En el supuesto en que el hecho causante de la protección por cese de actividad se produzca mientras el trabajador autónomo se encuentre en situación de incapacidad temporal, éste seguirá percibiendo la prestación por incapacidad temporal, en la misma cuantía que la prestación por cese de actividad, hasta que la misma se extinga en cuyo momento pasará a percibir, siempre que reúna los requisitos legalmente establecidos, la prestación económica por cese de actividad que le corresponda. En tal caso, se descontará del período de percepción de la prestación por cese de actividad, como ya consumido, el tiempo que hubiera permanecido en la situación de incapacidad temporal a partir de la fecha de la situación legal de cese de actividad.

En este caso, la cotización a cargo del órgano gestor se realizará exclusivamente a partir de la fecha en la que se inicie el pago de la prestación por cese de actividad y por el período de la misma que reste hasta su extinción. El trabajador autónomo tendrá la obligación de comunicar y acreditar la situación de cese de actividad al órgano gestor que abona la prestación de incapacidad temporal dentro de los 15 días siguientes al que se produce el cese de actividad. Por su parte, la solicitud de la protección por cese de actividad debe hacerse una vez extinguida la incapacidad temporal, acreditando la situación legal de cese de actividad ante la entidad $u$ órgano gestor de esa protección en los 15 días hábiles siguientes al día de extinción de la incapacidad.

b) Si durante la percepción de la prestación económica por cese de actividad el trabajador autónomo pasa a la situación de incapacidad temporal que constituya recaída de un proceso anterior iniciado con anterioridad a la situación legal de cese en la actividad, percibirá la prestación por esta contingencia en cuan- 
tía igual a la prestación por cese en la actividad. En este caso, y en el supuesto de que el trabajador autónomo continuase en situación de incapacidad temporal una vez finalizado el período de duración establecido inicialmente para la prestación por cese en la actividad, seguirá percibiendo la prestación por incapacidad temporal en la misma cuantía en la que la venía percibiendo.

c) Cuando el trabajador autónomo esté percibiendo la prestación por cese en la actividad y pase a la situación de incapacidad temporal que no constituya recaída de un proceso anterior iniciado anteriormente, percibirá la prestación por esta contingencia en cuantía igual a la prestación por cese en la actividad. En este caso, y en el supuesto de que el trabajador autónomo continuase en situación de incapacidad temporal una vez finalizado el período de duración establecido inicialmente para la prestación por cese en la actividad, seguirá percibiendo la prestación por incapacidad temporal en cuantía igual al 80\% del IPREM mensual.

d) El período de percepción de la prestación por cese de actividad no se ampliará como consecuencia de que el trabajador autónomo pase a la situación de incapacidad temporal. Durante dicha situación, el órgano gestor de la prestación se hará cargo de las cotizaciones a la Seguridad Social, hasta el agotamiento del período de duración de la prestación al que el trabajador autónomo tuviere derecho.

$Y$ respecto a las contingencias de maternidad y paternidad deben considerarse, asimismo, las siguientes reglas:

a) En el supuesto en que el hecho causante de la protección por cese de actividad se produzca cuando el trabajador autónomo se encuentre en situación de maternidad o paternidad, se seguirá percibiendo la prestación por maternidad o por paternidad hasta que las mismas se extingan; una vez que se extinga la prestación por maternidad o paternidad se podrá solicitar en el plazo de los 15 días hábiles siguientes la protección por cese de actividad, y siempre que se reúnan los requisitos exigidos, el derecho nacerá al día siguiente al de extinción de la prestación de maternidad o paternidad.

b) Cuando el beneficiario esté percibiendo la protección por cese de actividad y pase a la situación de maternidad o paternidad, se interrumpirá la prestación y la cotización a la Seguridad Social y pasará a percibir esas prestaciones gestionadas directa- 
mente por su órgano gestor. Una vez extinguida la prestación por maternidad o por paternidad el ente gestor de dichas prestaciones lo comunicará al órgano gestor de la protección por cese de actividad que reanudará de oficio esa protección por la duración, cuantía y cotización a la Seguridad Social pendiente en el momento de la suspensión.

\section{Régimen de obligaciones, infracciones y sanciones}

a) Constituyen obligaciones de los trabajadores autónomos solicitantes y beneficiarios de la protección por cese de actividad ${ }^{61}$ :

1. Solicitar al mismo órgano gestor con el que tengan concertada las contingencias profesionales la cobertura de la protección por cese de actividad.

2. Cotizar por la aportación correspondiente a la protección por cese de actividad.

3. Proporcionar la documentación e información que resulten necesarios a los efectos del reconocimiento, suspensión, extinción o reanudación de la prestación.

4. Solicitar la baja en la prestación por cese de actividad cuando se produzcan situaciones de suspensión o extinción del derecho o se dejen de reunir los requisitos exigidos para su percepción, en el momento en que se produzcan dichas situaciones.

5. No trabajar por cuenta propia o ajena durante la percepción de la prestación.

6. Reintegrar las prestaciones indebidamente percibidas.

7. Comparecer a requerimiento del órgano gestor y estar a disposición del Servicio Público de Empleo de la correspondiente comunidad autónoma, o del Instituto Social de la Marina, a fin de realizar las actividades formativas, de orientación profesional y de promoción de la actividad emprendedora a las que se les convoque. No obstante, los trabajadores autónomos que hayan cumplido la edad ordinaria de jubilación quedan exentos de cumplir esta obligación.

8. Participar en acciones específicas de motivación, información, orientación, formación, reconversión o inserción profesional para incrementar su ocupabilidad, que se determinen por el ór-

61 Cfr. artículo 17 de la Ley 32/2010, en relación con el artículo 29 del Real Decreto 1541/2011. 
gano gestor, por el Servicio Público de Empleo de la correspondiente comunidad autónoma, o por el Instituto Social de la Marina, en su caso.

9. Cumplir las exigencias del compromiso de actividad. A estos efectos, los beneficiarios deberán estar a disposición del Servicio Público de Empleo correspondiente, para lo cual deberán inscribirse y permanecer inscritos en el mismo durante el periodo de percepción de la prestación por cese de actividad. La inscripción quedará recogida en el marco del Sistema de Información de los Servicios Públicos de Empleo

b) En materia e infracciones y sanciones, se estará a lo dispuesto en el Texto Refundido de la Ley sobre infracciones y sanciones en el orden social, aprobado por Real Decreto Legislativo 5/2000, de 4 de agosto.

En íntima conexión con las infracciones y sanciones, merece especial atención el procedimiento de reintegro de prestaciones indebidamente percibidas ${ }^{62}$. De este modo, corresponde al órgano gestor la declaración como indebida de la prestación, en los siguientes supuestos:

a) Cuando se incumpla la obligación de participar en acciones específicas de motivación, información, orientación, formación, reconversión o inserción profesional para incrementar su ocupabilidad.

b) Cuando sea revocado el derecho a la prestación por cese de actividad.

c) En los supuestos en los que las prestaciones hayan sido indebidamente percibidas como consecuencia de errores materiales o de hecho y los aritméticos, así como por la constatación de omisiones o inexactitudes en las declaraciones del beneficiario.

d) En los demás supuestos en los que se produzca cualquier situación que genere un cobro indebido.

62 Cfr. Disposición Adicional quinta de la Ley 32/2010, en relación con el artículo 31 del Real Decreto 1541/2011. 